\title{
Journal of Bacteriology and

\section{Impact of Salvia and Peppermint Oil on the In Vitro Survival of Demodex Mites}

\author{
Aleksandra Sędzikowska ${ }^{1^{*}}$, Maciej Osęka ${ }^{2}$, Beata Roman $^{3}$ and Emilia Jaremko ${ }^{3}$ \\ ${ }^{1}$ Department of General Biology and Parasitology, Medical University of Warsaw, Poland \\ ${ }^{2}$ Ofta Ltd., ul. Mleczna 8, 03-667 Warsaw, Poland \\ ${ }^{3}$ Verco Sp. z o.o., Warsaw, Poland
}

*Corresponding author: Aleksandra Sędzikowska, Department of General Biology and Parasitology, Medical University of Warsaw, Poland, ul. Chalubinskiego 5, 02-004 Warsaw, Poland, Tel: +48 618691363; Fax: 482262853 50; E-mail: aleksandra.sedzikowska@wum.edu.pl

Received date: January 31, 2015; Accepted date: June 05, 2015; Published date: June 11, 2015

Copyright: @ 2015 Sędzikowska, et al. This is an open-access article distributed under the terms of the Creative Commons Attribution License, which permits unrestricted use, distribution, and reproduction in any medium, provided the original author and source are credited.

\begin{abstract}
Demodicosis is a medical condition caused by presence of Demodex mites. Mites may cause ocular demodicosis with symptoms such as burning and itching of eyelids. Currently, several drugs are available for the treatment of demodicosis. However, their use carries a risk of serious side effects. According to recent studies, substances contained in some plant-derived essential oils kill Demodex mites. Good efficacy of tea tree oil against Demodex sp. has been reported. However, some patients develop allergic reactions and ocular irritation in the course of tea tree oil treatment. Tests with essential oils showed that salvia and peppermint oils rapidly kill Demodex-in 7 and 11 minutes, respectively. Salvia is known as a valuable herb and is used to treat eye disease. Therefore, salvia essential oil could be an alternative treatment for demodicosis.
\end{abstract}

Keywords: Demodex, Salvia oil; Peppermint oil; Essential oils

\section{Introduction}

The Demodicidae family includes strictly specialized parasitic mites living in the skin, hair follicles or outer epidermal layers. Demodex mites show strong host-species specificity. Up to now, two humanspecific Demodex species have been described: Demodex folliculorum and Demodex brevis. These mites may cause ocular demodicosis with symptoms such as burning and itching of eyelids. Demodex plays an important role in Demodex blepharitis, meibomian gland dysfunction, conjunctival inflammation or corneal lesions [1].

Demodicosis is a major medical problem in dermatology and ophthalmology because it is chronic, its symptoms vary in intensity, early diagnosis is difficult, and inappropriate treatment (e.g. with steroids) leads to unwanted consequences. Currently, there are several drugs available for treating demodicosis. However, most of them are applied in veterinary medicine, and their use carries the risk of serious side effects.

Gao et al. [2] reported good effects of tea tree oil (TTO) on Demodex sp., both in vitro and in vivo. The same group [3] tested an ointment containing 5\% tea tree oil in Demodex-infested patients with chronic anterior blepharitis. The authors indicated that daily massage with the use of the ointment can partially or completely relieve subjective symptoms of ocular demodicosis. Koo et al. [4] described TTO as safe and acceptable for clinical use in patients with Demodex mites but they mentioned allergic reactions and ocular irritation as complications of TTO treatment.

Development of new, alternative substances with demodicidal activity could contribute to greater efficacy and tolerance of skin and ocular demodicosis therapy.

\section{Materials and Methods}

The study material consisted of vital Demodex mites collected from eyelashes of patients who were subject to examination for presence of the mites. Four eyelashes were collected from each eye, by means of tweezers. Immediately after collection, the eyelashes were placed on a slide and examined under 200-400x magnification [5]. Identified Demodex mites were assessed for motility on the glass slide under 200-400x magnification. Only adult forms of Demodex mites were tested [6]. Vital mites were placed in a drop of tested substance, and closed in a humid chamber to prevent the applied substance from evaporating. Motility of the mites was observed at the different time intervals: continuously from 0 to minute 15; every 5 minutes from minute 15 to minute 180; from minute 180 onwards, every 2 hours. When the mites' motility was decreasing clearly, the observation was more frequent. Movements of the legs were used to judge whether mites were alive and the time when they ceased to show vital signs was recorded [6].

Survival time of Demodex was measured starting from application of the substance on mites and ending when no movement of Demodex mites was observed. Survival time of the mites in saline was used as control. Effects of salvia (100\% Salvia hispanica, Avicenna-Oil) and peppermint essential oils (100\% Mentha piperita, Avicenna-Oil) were studied. Also salvia oil with liquid paraffin and triglycerides of caprylic and capric acids (Croda) were tested.

Statistical analysis of obtained results was performed with the use of Microsoft Excel 2010. Mean survival time and standard deviation (SD) was calculated.

\section{Results}

Demodex in vitro survival time in studied substances is presented in Table 1. 


\begin{tabular}{|l|l|l|l|l|}
\hline \multicolumn{1}{|c|}{ Agent } & $\begin{array}{c}\text { Number } \\
\text { of tested } \\
\text { Mites }\end{array}$ & $\begin{array}{c}\text { mean survival time } \\
\mathbf{( \pm ~ S D})\end{array}$ & $\begin{array}{c}\text { minimum } \\
\text { survival } \\
\text { time }\end{array}$ & $\begin{array}{c}\text { maximum } \\
\text { survival } \\
\text { time }\end{array}$ \\
\hline saline & 15 & $82 \mathrm{~h}( \pm 35 \mathrm{~h})$ & $35 \mathrm{~h}$ & $156 \mathrm{~h}$ \\
\hline $100 \%$ salvia oil & 21 & $7 \mathrm{~min}( \pm 3,2 \mathrm{~min})$ & $2 \mathrm{~min}$ & $14 \mathrm{~min}$ \\
\hline $50 \%$ salvia oil & 18 & $32 \mathrm{~min}( \pm 4,2 \mathrm{~min})$ & $30 \mathrm{~min}$ & $45 \mathrm{~min}$ \\
\hline $25 \%$ salvia oil & 15 & $85 \mathrm{~min}( \pm 30,4 \mathrm{~min})$ & $31 \mathrm{~min}$ & $150 \mathrm{~min}$ \\
\hline $12,5 \%$ salvia oil & 11 & $119 \mathrm{~min}( \pm 35,5 \mathrm{~min})$ & $61 \mathrm{~min}$ & $175 \mathrm{~min}$ \\
\hline $3 \%$ salvia oil & 5 & $60 \mathrm{~h} \pm 9,4 \mathrm{~h})$ & $48 \mathrm{~h}$ & $72 \mathrm{~h}$ \\
\hline $\begin{array}{l}1 \% \text { salvia oil } \\
\text { with paraffin }\end{array}$ & 9 & $135 \mathrm{~h} \pm 7,9 \mathrm{~h})$ & $120 \mathrm{~h}$ & $144 \mathrm{~h}$ \\
\hline $\begin{array}{l}1 \% \text { salvia oil } \\
\text { with } \\
\text { triglycerides }\end{array}$ & 8 & $80 \mathrm{~h} \pm 7,9 \mathrm{~h})$ & $72 \mathrm{~h}$ & $92 \mathrm{~h}$ \\
\hline salvia extract & 8 & $48 \mathrm{~h} \pm 6,6 \mathrm{~h})$ & $32 \mathrm{~h}$ & $52 \mathrm{~h}$ \\
\hline $\begin{array}{l}100 \% \\
\text { peppermint oil }\end{array}$ & 18 & $11 \mathrm{~min}( \pm 3,8 \mathrm{~min})$ & $6 \mathrm{~min}$ & $19 \mathrm{~min}$ \\
\hline $\begin{array}{l}50 \% \\
\text { peppermint oil }\end{array}$ & 9 & $43 \mathrm{~min}( \pm 14,5 \mathrm{~min})$ & $28 \mathrm{~min}$ & $70 \mathrm{~min}$ \\
\hline $\begin{array}{l}25 \% \\
\text { peppermint oil }\end{array}$ & 11 & $110 \mathrm{~min}( \pm 44,4 \mathrm{~min})$ & $40 \mathrm{~min}$ & $183 \mathrm{~min}$ \\
\hline $\begin{array}{l}12,5 \% \\
\text { peppermint oil }\end{array}$ & 12 & $157 \mathrm{~min}( \pm 45,5 \mathrm{~min})$ & $77 \mathrm{~min}$ & $211 \mathrm{~min}$ \\
\hline & & & & \\
\hline
\end{tabular}

Table 1: Effects of salvia and peppermint oil on Demodex survival time.

\section{Discussion}

Tests of essential oils revealed that salvia and peppermint oils killed Demodex mites in a short time - $100 \%$ salvia oil kills mites in 7 minutes and $100 \%$ peppermint oil in 11 minutes. For comparison, tea tree oil kills in 3,7 minutes [2]. However, some patients present allergic reactions after using TTO. Therefore, examining and testing other essential oils could help in developing alternative products for treating demodicosis. Especially salvia is known as a valuable herb, which produces useful secondary metabolites like terpenes [7]. In TTO, Terpinen-4-ol was found to be the most active ingredient that kills Demodex mites [6]. Both salvia essential oil and salvia extracts were studied. Salvia oil from the chia plant eliminated Demodex effectively and rapidly, while salvia extract proved to be less effective in that the mean survival time was as long as 2 days. Salvia extracts contain only $2 \%$ to $3 \%$ essential oils. This suggests that it is solely the terpenes, contained in essential oils, that decrease vitality of Demodex mites.

Liquid paraffin and triglycerides of caprylic and capric acids are one of the basic components of the base emulsion systems. Ointment composition may additionally strengthen or weaken the effect of acaricides therefore triglycerides and paraffin were tested. Demodex mites survived longer in $1 \%$ salvia oil with paraffin $(135 \mathrm{~h})$ than in triglycerides $(80 \mathrm{~h})$. This suggests that an ointment for patients with demodicosis should contain appropriate excipients.

Salvia is used to treat eye disease, acne, headache and oral or pharyngeal inflammation. Recently, other uses have been suggested. Salvia or chia essential oils have mosquito larvicidal activity $[7,8]$. Salvia essential oils were able to inhibit the growth of the cancer cells [9]. Also Salvia officinalis aroma was found to significantly enhance memory in cognitive tasks [10]. Jeong et al. used a topical formulation containing $4 \%$ chia seed oil for 8 weeks. They observed that topical chia seed oil is effective for pruritus and xerosis treatment and is also beneficial for skin moisturization in healthy volunteers with xerotic pruritus [11].

Peppermint oil killed Demodex mites less effectively compared to salvia oil. This shows that the efficacy of essential oils from different plant species is not equal.

Salvia essential oil shows promising effects and requires further investigations to prove its usefulness in demodicosis treatment.

\section{References}

1. Liu J, Sheha H, Tseng SC (2010) Pathogenic role of Demodex mites in blepharitis. Curr Opin Allergy Clin Immunol 10: 505-510.

2. Gao YY, Di Pascuale MA, Li W, Baradaran-Rafii A, Elizondo A, et al. (2005) In vitro and in vivo killing of ocular Demodex by tea tree oil. Br J Ophthalmol 89: 1468-1473.

3. Gao YY, Xu DL, Huang IJ, Wang R, Tseng SC (2012) Treatment of ocular itching associated with ocular demodicosis by $5 \%$ tea tree oil ointment. Cornea 31: 14-17.

4. Koo H, Kim TH, Kim KW, Wee SW, Chun YS, et al. (2012) Ocular surface discomfort and Demodex: effect of tea tree oil eyelid scrub in Demodex blepharitis. J Korean Med Sci 27: 1574-1579.

5. Garbacewicz A, Jaworski J, Grytner-Zięcina B (2012) Demodex mite infestation in patients with and without rheumatoid arthritis. Acta Parasitol 57: 99-100.

6. Tighe S, Gao YY, Tseng SC (2013) Terpinen-4-ol is the Most Active Ingredient of Tea Tree Oil to Kill Demodex Mites. Transl Vis Sci Technol 2: 2 .

7. Ali A, Tabanca N, Demirci B, Blythe EK, Ali Z, et al. (2015) Chemical composition and biological activity of four salvia essential oils and individual compounds against two species of mosquitoes. J Agric Food Chem 63: 447-456.

8. Mathew J, Thoppil JE (2011) Chemical composition and mosquito larvicidal activities of Salvia essential oils. Pharm Biol 49: 456-463.

9. Russo A, Cardile V, Graziano AC, Formisano C, Rigano D, et al. (2014) Comparison of essential oil components and in vitro anticancer activity in wild and cultivated Salvia verbenaca. Nat Prod Res .

10. Moss L, Rouse M, Wesnes KA, Moss M (2010) Differential effects of the aromas of Salvia species on memory and mood. Hum Psychopharmacol 25: 388-396.

11. Jeong SK, Park HJ, Park BD, Kim IH (2010) Effectiveness of Topical Chia Seed Oil on Pruritus of End-stage Renal Disease (ESRD) Patients and Healthy Volunteers. Ann Dermatol 22: 143-148. 